\title{
Alumina/tungsten nano-composites obtained by Spark Plasma Sintering
}

\section{T. Rodriguez-Suarez ${ }^{1}$, L.A. Díaz ${ }^{1}$, R. Torrecillas ${ }^{1}$, S. Lopez-Esteban ${ }^{1}$, W.-H. Tuan ${ }^{2}$, M. Nygren $^{3}$ and J.S. Moya $*^{4}$}

\author{
${ }^{1}$ Centro de Investigación en Nanomateriales y Nanotecnología (CINN). Principado de Asturias, Consejo \\ Superior de Investigaciones Científicas (CSIC), Universidad de Oviedo (UO). Parque Tecnológico de \\ Asturias, 33428 Llanera, (Asturias) Spain. \\ ${ }^{2}$ Department of Materials Science and Engineering, National Taiwan University, Taipei 106, Taiwan \\ ${ }^{3}$ Inorganic Chem., Arrh. Lab. Stockholm University, 10691 Stockholm, Sweden \\ ${ }^{4}$ Instituto de Ciencia de Materiales de Madrid (ICMM), Consejo Superior de Investigaciones Científicas \\ (CSIC), C/ Sor Juana Inés de la Cruz, 3, 28049, Cantoblanco, Madrid, Spain \\ *Author to whom all correspondence should be addressed: \\ e-mail: jsmoya@icmm.csic.es \\ Tel/Fax: + 34 913349083/+ 34913720623
}

\begin{abstract}
In the present work, the parameters controlling the Alumina/W nano-powders Spark Plasma Sintering (SPS) process are studied. The important and crucial role of C diffusion from the SPS die in the microstructure, fraction of porosity and new phases formation $\left(\mathrm{W}_{2} \mathrm{C}\right)$ is discussed. It is also pointed out the importance of the processing parameters of the starting powder on the density and mechanical properties of the final compacts. In this regard, dense Alumina/nW compacts containing 4 vol. $\% \mathrm{~W}$ with a hardness value as high as $24.6 \pm 0.9 \mathrm{GPa}$ were obtained.
\end{abstract}

Keywords: A. Ceramic-matrix composites (CMCs), A. Nano composites, D. Hardness testing, E. Sintering, Spark Plasma Sintering 


\section{Introduction}

Nowadays, ceramic/metal nano-composites are considered of great interest in materials science due to the singular properties they can present [1]. New materials synthesis and devices require a deep knowledge and a controlled microstructure handling, on atomic levels.

This particular case of alumina/W nano-composites have been chosen because of the commercial availability of alumina nano-powder and because tungsten thermal expansion coefficient is lower than the one of alumina $\left(4.5 \cdot 10^{-6} \mathrm{~K}^{-1}\right.$ and $8.5 \cdot 10^{-6} \mathrm{~K}^{-1}$, respectively). The latter is a very important factor to take into account in order to minimize residual stresses at ceramic/metal interfaces. Then, metal nano-particles will be subjected to the more stable compressive stresses in the final compact.

It is well known that nano-metric metal particles present a less ductile behaviour compared to micrometric levelled ones [2]. In the particular case of tungsten, it posses a extremely high $\mathrm{G}$ module value (161 GPa), and due to the linear dependence that can be found between this property and hardness, the expected $\mathrm{H}_{\mathrm{V}}$ value would be as high as $30 \mathrm{GPa}[1]$.

Studies of the alumina/W system can be found in the scientific literature, at the micrometric scale in part due to those compounds, in this system, exhibit useful properties for various applications in different industrial and technological fields [3]. In this work, a new processing route is proposed comprising a controlled synthesis of tungsten nano-particles over alumina nano-grains and employing the Spark Plasma Sintering technique for retaining nano-particles sizes and distribution in the final compact. In the present study, we report the important effect of powder processing, sintering procedure and carbon impurities on the final microstructures and mechanical properties of the obtained nano-composites. 


\section{Nano-composites Processing and Characterization}

\subsection{Powder processing}

\subsubsection{Starting materials}

The following commercially available powders were used: (1) $\mathrm{WCl}_{6}$ (Tungsten (VI) chloride $99.9 \%$, Aldrich, Germany) and (2) $\alpha$-alumina powder (99.99\%, Taimei Chemical Co., Ltd., Japan) with an average particle size of $\mathrm{d}_{50}=300 \pm 50 \mathrm{~nm}$.

\subsubsection{Synthesis of nano-powders}

In order to study the influences of $\mathrm{C}$ and aggregates presence on the nanopowders Spark Plasma Sintering behaviour, before the deposition of tungsten nanoparticles onto the alumina grains, the alumina commercial powder was treated as follows:

(1) Not processed labelled as "as received" below

(2) Calcined at $750{ }^{\circ} \mathrm{C}$ for $2 \mathrm{~h}$ in order to remove any organic additive present in the commercial powder and subsequently passed through a $63 \mu \mathrm{m}$ sieve (alumina aggregates were formed), and

(3) Calcined at $750{ }^{\circ} \mathrm{C}$ for 2 hours, sieved down to $63 \mu \mathrm{m}$ and attrition milled during 30 minutes in alcoholic media (anhydrous $99.97 \%$ ethanol) in order to break aggregates.

Powder mixtures with different metallic contents $(1-10$ vol. \%) were prepared. Alumina powders, pretreated in one of the two ways described above or "as received", were weighed and dispersed in anhydrous $99.97 \%$ ethanol and a solution of tungsten (VI) chloride $\left(\mathrm{WCl}_{6}\right)$ in ethanol (with the corresponding concentration needed for obtaining the desired final metallic content) was added drop wise [4]. When alumina was calcined first and then attrition milled in ethanolic media, the powder was not dried 
but was directly composed with the corresponding $\mathrm{WCl}_{6}$ solution. The slurries were first heated under magnetic stirring at $70{ }^{\circ} \mathrm{C}$ and subsequently in air at $60{ }^{\circ} \mathrm{C}$ for $24 \mathrm{~h}$ in order to start nucleation and eliminate any traces of alcohol. The dried powders were crushed and thermally treated in air at $600{ }^{\circ} \mathrm{C}$ for $1 \mathrm{~h}$ to eliminate organic compounds and promote the formation of tungsten (VI) oxide $\left(\mathrm{WO}_{3}\right)$ particles onto the alumina grains. $\mathrm{X}$-Ray analysis was performed to control the decomposition of the tungsten precursor into the most stable oxide $\left(\mathrm{WO}_{3}\right)$. The powders were then sieved down to $63 \mu \mathrm{m}$ before being reduced. Reduction of $\mathrm{WO}_{3}$ to tungsten was carried out at $900{ }^{\circ} \mathrm{C}$ for $2 \mathrm{~h}$ in a pure $\mathrm{H}_{2}$ atmosphere.

\subsection{Spark Plasma Sintering (SPS)}

The spark plasma sintering was chosen as it is a relatively novel technique that makes it possible to obtain dense nano-composites having the nano-structured feature of the ceramic/metal mixed powder previously processed. Moreover, it provides many advantages since very rapid sintering slopes can be achieved, giving uniform densities in the final compact with the addition of less additives and quite easy handling and low processing costs [5]. For comparison, monolithic alumina specimens were also SPSed.

The compaction of the obtained powders was performed in different spark plasma sintering furnaces (Dr Sinter 2050, SPS Syntex Inc., Japan, and FCT Systeme GMBH, HPD 25, Germany) for comparing the slight differences in operating conditions for both kind of commercial SPS equipments today available in the market, essentially temperature measurement and vacuum reached (pyrometer measuring temperature in a vertical way (on top of the compact) in the case of FCT furnace and horizontal temperature measurement for the Dr Sinter furnace, vacuum level reached around $10^{-2}$ mbar in the FCT furnace and $10^{-5} \mathrm{mbar}$ in the case of the Dr Sinter furnace). Cylindrical 
samples with a diameter ranging from 12 to $30 \mathrm{~mm}$ and height of 2-4 $\mathrm{mm}$ were prepared as follows; i) the samples were heated from room temperature to $600{ }^{\circ} \mathrm{C}$ at a rate of 600 ${ }^{\circ} \mathrm{C} / \mathrm{min}$, using a pressure of $\sim 10 \mathrm{MPa}$; ii) From $600{ }^{\circ} \mathrm{C}$ to $1100{ }^{\circ} \mathrm{C}$ a heating rate of 200 ${ }^{\circ} \mathrm{C} / \mathrm{min}$ and a pressure of $\sim 10 \mathrm{MPa}$ was applied; iii) From $1100{ }^{\circ} \mathrm{C}$ to $1350{ }^{\circ} \mathrm{C}$ or 1400 ${ }^{\circ} \mathrm{C}$ a heating rate of $50{ }^{\circ} \mathrm{C} / \mathrm{min}$ and pressure of 60 or $100 \mathrm{MPa}$, respectively, was used; iv) Finally the samples were heat treated at final temperature for $3 \mathrm{~min}$. It is worth noting that when pressure of $60 \mathrm{MPa}$ was used a temperature of $1400{ }^{\circ} \mathrm{C}$ was required for obtaining dense samples, that is $50^{\circ} \mathrm{C}$ higher than the temperature needed for obtaining dense compacts when a pressure of $100 \mathrm{MPa}$ was applied.

\subsection{Compacts characterization}

\subsubsection{Microstructural characterization}

The microstructural features of the obtained nano-sized powder as well as the SPSed samples were studied in a transmission electron microscopy TEM (Jeol microscope, model FXII, JEM 2000, operating at $200 \mathrm{kV}$ ). Reflected light optical microscopy was performed with a Leica DMRM microscope.

Fracture surfaces for the different compacts were studied in a SEM model DSM 960, Zeiss Thornwood, NY.

\subsubsection{X-Ray Characterization}

$\mathrm{X}$-Ray diffraction analysis (XRD) of the starting and processed powders and the final compacts obtained was performed using $\mathrm{Cu} K \alpha$ radiation (Bruker D8 diffractometer). In the final compacts case, cross-sections or the external dense surfaces were analyzed by this technique. 


\subsubsection{Mechanical Properties evaluation}

The Vickers hardness, $\mathrm{H}_{\mathrm{V}}$, of the SPSed samples was determined by microindentation (Buehler model Micromet 5103) on sample surfaces polished down to 1 micron, applying a $1.96 \mathrm{~N}$ load with an indentation time of $10 \mathrm{~s}$. For each sample, 30 indentations were made and 60 diagonals length were measured in order to have a representative mean value of the hardness. The magnitude of the Vickers hardness was determined according to,

$$
H_{V}=1.853 \frac{P}{d^{2}}
$$

where $P$ is the applied load (in $\mathrm{N}$ ) and $d$ is the diagonal length (in $\mathrm{m}$ )

The toughness, $\mathrm{K}_{\mathrm{IC}}$, was also determined by microindentation (diamond indenter Leco $100-A$, St. Joseph, MI), but, for this specific property, the applied load was $98 \mathrm{~N}$ with an indentation time of $10 \mathrm{~s}$. The fracture toughness was calculated using the formula given by Miranzo and Moya [6],

$$
\begin{aligned}
& K_{I C}=\frac{0.047 \cdot P}{\left(d^{0.42} \cdot c^{1.08}\right) \cdot\left[f\left(E / H_{V}\right)\right]} ; c / d>2.8 \\
& K_{I C}=\frac{0.0232 \cdot P}{\left(d \cdot c^{1 / 2}\right) \cdot\left[f\left(E / H_{V}\right)\right]} ; c / d<2.8 \\
& \text { Where }\left[f\left(E / H_{V}\right)\right]=\frac{0.768 \cdot\left(E / H_{V}\right)}{0.05+0.612 \cdot \ln \left(E / H_{V}\right)}-2
\end{aligned}
$$

and $\mathrm{H}_{\mathrm{V}}$ is the hardness (given by Eq. 1), $\mathrm{P}$ the applied load, $\mathrm{E}$ the elastic modulus and $\mathrm{d}$ and $\mathrm{c}$ are the indentation diagonal and crack length, respectively.

\section{Results and Discussion}


Two different sintering cycles were selected as they give more dense materials:

(i) $1350^{\circ} \mathrm{C} / 3 \mathrm{~min} / 100 \mathrm{MPa}$ and (ii) $1400^{\circ} \mathrm{C} / 3 \mathrm{~min} / 60 \mathrm{MPa}$. Compacts obtained were characterized and tested.

\subsection{Microstructual characterization}

\subsubsection{SPSed at $1350^{\circ} \mathrm{C} / 3 \mathrm{~min} / 100 \mathrm{MPa}$}

Cross-sections of SPSed disks were polished and microscopically studied. In Fig. 1 optical micrographs corresponding to the polished sections of compacts processed by one of the three different ways described in section 2.1.2 can be observed. It is shown that just dense materials were obtained when the alumina powder was processed according to route (2) described above. When alumina processed according to routes (1) or (3) were used, compacts having a dense surface section were obtained while the inner part of the sample always contained porosity (open porosity $\geq 20 \%$ ). This was observed independently of the SPS furnace used or the sintering cycle chosen.

A more extended microstrusture study was performed using the SEM. In the case of dense materials processed according to route (2), peculiar microstructures were observed containing large alumina aggregates $(<63 \mu \mathrm{m}$ and medium agglomeration size of $28 \pm 14 \mu \mathrm{m})$ present in the $50 \%$ of the microstructure surrounded by W nano- $(<150$ $\mathrm{nm}$ ) and sub-micron sized particles (coarsened particles between $300-600 \mathrm{~nm}$ in size, mainly aggregated by the presence of $\mathrm{C}$ in the system during sintering) attached to smaller alumina grains $\left(\mathrm{d}_{50} \approx 320 \pm 50 \mathrm{~nm}\right)$. A fracture surface corresponding to a dense alumina/2 vol. $\% \mathrm{~W}$ SPSed compact at $1350^{\circ} \mathrm{C} / 3 \mathrm{~min} / 100 \mathrm{MPa}$ is shown in Fig.2, where (a) is a general overview and (b)-(d) are (a) close-ups. The peculiar microstructure described above can be clearly observed in these figures. 
It could be determined by EDS- analysis that tungsten was present, in a less significant amount, inside the alumina aggregates (Table 1). A more extended study of these large aggregates by TEM, showed that very small $\mathrm{W}$ nano-particles $\left(\mathrm{d}_{50}=16 \mathrm{~nm}\right)$ were mostly located at triple points but also at alumina grain boundaries providing a pinning effect and constraining alumina grains sizes to $<300 \mathrm{~nm}\left(\mathrm{~d}_{50}=200 \pm 50 \mathrm{~nm}\right)$, as shown in Fig. 3. The $\mathrm{W}$ concentration inside the aggregates was $50 \%$ the theoretical one. The presence of W nano-particles inside the aggregates is not so unexpected, due to the preparation procedure of tungsten nano-particles. When the alumina slurry is prepared, the aggregates present certain porosity allowing penetration of $\mathrm{WCl}_{6}$ solution. Fracture surfaces of compacts prepared according to routes (1) to (3) were also studied in the SEM (Fig. 4). In the case of composites processed according to route (1), the outer dense parts of the specimens did not present such aggregates, tungsten was well dispersed yielding homogeneous composites (Fig. 4a). On the other hand, in the porous inner parts of the specimens, abnormal alumina grain growth, also known as "dynamic ripening" was also observed as shown in Fig. 4b. This micrograph shows how alumina has grown in an exaggerated way embedding tungsten nano-particles during the sintering process. Thus well-faceted large alumina grains of sizes between 2 and $10 \mu \mathrm{m}$ are present. On the contrary, in between these large grains, alumina grains of sizes between $300 \mathrm{~nm}$ and $1 \mu \mathrm{m}$ are present.

This exaggerated grain growth phenomena has been previously observed in other materials like ( $\mathrm{Ba}, \mathrm{Sr}) \mathrm{TiO}_{3}[7]$ and $\alpha$-sialon [8].

Below a critical temperature, the grain growth progresses very slowly, while above it, the grain growth takes place dramatically fast. It is essential to define a temperature range, or kinetic window, where materials can be sintered without exceeding that critical temperature [8]. 
The presence of these well-faceted large alumina grains can be related to the high heating rates used in the SPS processor or to the electrical field the material is exposed during the sintering. To the extent vapour formation takes place, enhance grain growth is expected.

Monolithic alumina sintered differently. Dense compacts were obtained and no abnormal alumina grain growth was observed. A SEM micrograph of the fracture surface of monolithic alumina SPSed at $1350^{\circ} \mathrm{C} / 3 \mathrm{~min} / 100 \mathrm{MPa}$ is shown in Fig. $4 \mathrm{~d}$. Intergranular fracture features are mainly observed. The measured mean SPSed alumina grain size was $2.5 \pm 1 \mu \mathrm{m}$.

Comparing microstructures depicted in Fig. 2 and 4 it can be stated that $\mathrm{W}$ nanoparticles prevent alumina grain growth. This is known as "pinning effect".

\subsubsection{SPSed at $1400^{\circ} \mathrm{C} / 3 \mathrm{~min} / 60 \mathrm{MPa}$}

Fracture surfaces of samples SPSed at $1400^{\circ} \mathrm{C} / 3 \mathrm{~min} / 60 \mathrm{MPa}$ and processed by route (2) were studied in the SEM. In this case, dense composites with the presence of large alumina aggregates were obtained.

The microstructure contained in this case larger alumina grains $\left(\mathrm{d}_{50} \approx 5.75 \pm 1\right.$ $\mu \mathrm{m})$ and this is due to the use of a higher sintering temperature and a lower pressure.

Fracture surfaces of this composition and of monolithic alumina are shown in Fig. 5. Intergranular fracture features are mainly observed.

\subsection{Compositional characterization}

All SPSed compacts were X-rayed. The presence of a tungsten carbide, $\mathrm{W}_{2} \mathrm{C}$, was always noticed, independently of the processing route used or SPS furnace employed. The X-ray patterns of selected compacts are given in Fig. 6. 
As the sintering of the compact is taking place in a graphite die, it is reasonable to think that carbon can diffuse into the sample from the die and this process is promoted by the applied pressure. The formation of tungsten carbide, $\mathrm{W}_{2} \mathrm{C}$, is thermodynamically feasible in the temperatures range where the sintering takes place. $\Delta \mathrm{G}$ value varies between $-21.736 \mathrm{~kJ} / \mathrm{mol}$ at room temperature to $-34.694 \mathrm{~kJ} / \mathrm{mol}$ at 1350 ${ }^{\circ} \mathrm{C}$. By quantitative XRD analysis, the fraction of $\mathrm{W}_{2} \mathrm{C}$ formed ranged from $15-35 \%$ of the initial $\mathrm{W}$ volumetric content.

The presence of $\mathrm{W}_{2} \mathrm{C}$ does not favour the densification of the composites. Its density, $17.14 \mathrm{~g} / \mathrm{cm}^{3}$ is lower than the one for $\mathrm{W}, 19.25 \mathrm{~g} / \mathrm{cm}^{3}$, so a volume expansion is going to be induced inside the material during its formation. The molar volume change produced is around 16 vol.\%. This expansive magnitude is quite large and, to a certain extent, can counteract the uni-axial load applied during SPS process, yielding a non homogeneous material densification. On the other hand, $\mathrm{W}_{2} \mathrm{C}$ is a very rigid compound and, in this sense, it could also hinder grain boundary sliding during sintering.

\subsection{Densification and powders packing}

The different levels of densification achieved according to the processing ways can be rationalized considering (i) The starting green body density reached at the SPS die, and (ii) The presence of carbon:

(i) As it is stated by the principles of ceramics processing [9], continuous particle size distributions of the log-normal type used for ceramics have a maximum packing density of about $65 \%$. This packing density for a mono-size system can be increased above $75 \%$ by adding a specific proportion of a finer size that packs efficiently in the interstices among the coarse grains. In this sense, compacts processed according to routes (1) or (3) may present a lower green body density than the ones 
processed according to route (2). That is, when the starting powder was formed by large alumina aggregates and a fraction of smaller alumina grains that placed at the aggregates interstices during compaction, higher green body densities, when comparing to mono-size systems as in routes (1) and (3), were reached.

(ii) In this particular ceramic-metal system, carbon plays a crucial role during SPS and its presence comes from graphite die diffusion. Some authors have reported that where carbon is placed, special reducing conditions are created favouring interfacial diffusion and bonding [10] and, hence, densification. This happens when carbon acts as lubricant, but in our particular case, carbon does not favour densification since it reacts with $\mathrm{W}$ particles yielding $\mathrm{W}_{2} \mathrm{C}$.

For SPSed compacts processed according to route (2) $\mathrm{W}_{2} \mathrm{C}$ is expected to be located at interstices between large alumina aggregates, as shown in Fig. 3, being these interstices preferential pores for $\mathrm{C}$ diffusion; while inside these aggregates, $\mathrm{C}$ diffusion would be hindered and $\mathrm{W}$ would be present as a metallic phase.

On the other hand, SPSed compacts processed according to routes (1) and (3) present open porosity and $\mathrm{C}$ can diffuse along the whole samples. In this regard, densifications are inhomogeneous, as seen in Fig. 4, since plastic phase is replaced by a rigid one as carbon diffusion front propagates hindering densification.

Sintering kinetics is not perfectly understood due to the amount of parameters involved in the process and, moreover, carbon diffusion that in this particular case takes part as a reactant, is an external and uncontrollable process.

\subsection{Mechanical properties}

Hardness and toughness have been evaluated. Due to the observed porosity in all the specimens processed by routes (1) and (3) (open porosity $\geq 20 \%$ located at the inner 
part of the specimens), toughness could only be determined for the fully dense samples prepared according to route (2). Dense areas obtained for compacts processed by routes (1) or (3) were not wide enough for toughness evaluation by indentation according to the method described before, cracks were not well developed and hence, the method could not be applied.

\subsubsection{Vickers Hardness}

The samples prepared at 1350 and $1400{ }^{\circ} \mathrm{C}$ exhibit a similar trend in the plot of $\mathrm{H}_{\mathrm{V}}$ versus vol. \% $\mathrm{W}$ as seen in Fig. 7a. The SPSed samples prepared at $1350^{\circ} \mathrm{C} / 3 \mathrm{~min} / 100 \mathrm{MPa}$ were the one with highest $\mathrm{H}_{\mathrm{V}}$-value. This fact is supported by the observation that the mean grain size for this composite $(2.5 \pm 1 \mu \mathrm{m})$ is smaller than for the one prepared at $1400^{\circ} \mathrm{C} / 3 \mathrm{~min} / 60 \mathrm{MPa}\left(\mathrm{d}_{50} \approx 5.7 \pm 1 \mu \mathrm{m}\right)$.

The observed trend in Fig. 7a is similar to the one obtained in the case of alumina-nNi [11]. An increase of the $\mathrm{H}_{\mathrm{V}}$-value with the $\mathrm{nW}$ content is observed. Even considering that the theoretical model proposed by Pecharromán et al.[11] can not be applied in this particular case, the obtained value for the apparent aggregation threshold $f_{c i} \approx 4$ vol. $\%$ is not far away from the one expected if the $\mathrm{nW}$ particles would be homogeneously distributed (2.6 vol.\%) as in the case of $\mathrm{Al}_{2} \mathrm{O}_{3}-\mathrm{nNi}$ with a similar matrix grain size $(\sim 0.3 \mu \mathrm{m})$. We have to take into account that in the alumina/nW (4 vol. $\%)$ a fraction of metal is clearly agglomerated and other fraction is presented as $\mathrm{W}_{2} \mathrm{C}$.

\subsubsection{Toughness}

Toughness was evaluated for SPSed compacts of monolitithic alumina and its tungsten composites. The sample SPSed at $1400{ }^{\circ} \mathrm{C}$ exhibited higher toughness value than the one prepared at $1350{ }^{\circ} \mathrm{C}$ as seen in Fig. $7 \mathrm{~b}$, that in turn can be ascribed to 
different alumina grain sizes in these compacts. Alumina presents R-curve behaviour [12] much more pronounced than alumina-based composites as the second phase exert a pinning effect to the grain growth.

\section{Conclusions}

(i) Carbon diffusion plays a crucial role when SPS materials presenting carbon reactive phases, acting as a reactant and not as a lubricant. This issue is relevant and needs to be taken into account when spark plasma sintering carbon reactive metals or compounds (as for example, W, Ti, $\mathrm{TiO}, \mathrm{SiO}_{2}$, etc) especially when handling nano-particles where reactivity is enhanced.

(ii) Fully dense SPSed alumina/4 vol. $\% \mathrm{~W}$ with high hardness values $(\approx 25$ $\mathrm{GPa}$ ) were obtained when processing bi-modal grain size distribution favouring compaction and, hence, densification.

\section{Acknowledgements}

This work was supported by the European Union under the IP-NANOKER project FP6-515784-2, by the Spanish National Research Council (CSIC) through a bilateral cooperation with National Taiwan University under the 2006TW004 project and by the Spanish Ministry of Science and Innovation under the MAT2006-10249C02-01 project. 


\section{REFERENCES}

1. Moya JS, Lopez-Esteban S, Pecharromán C. The challenge of ceramic/metal microcomposites an nanocomposites. Prog In Mat Sci 2007;52:1017-1090.

2. Siegel RW. Nanostructured materials -mind over matter-. Nanostruct Mater 1993;3:118.

3. Kotek V. Metal Ceramic $\mathrm{Al}_{2} \mathrm{O}_{3}$-Tungsten Composites. Euro-Ceramics II 1993; Vol.II: Structural ceramics and composites:1685-1690.

4. Rodriguez-Suarez T, Díaz LA, Lopez-Esteban S, Pecharromán C, Esteban-Cubillo A, Gremillard L, Torrecillas R, Moya JS. Epitaxial growth of tungsten nanoparticles on alumina and spinel surfaces. Nanotechnology 2008;19:215605 (5pp).

5. Viswanathan V, Laha T, Balani K, Agarwal A, Seal S. Challenges and advances in nanocomposite processing techniques. Mats Sci and Eng R 2006;54:121-285.

6. Miranzo P, Moya JS. Elastic plastic indentation in ceramics: a fracture toughness determination method. Ceram Int 1984;10:147-152.

7. Liu J, Shen Z, Nygren M, Su B, Button TW. Spark Plasma Sintering Behaviour of Nano-Sized (Ba, Sr) $\mathrm{TiO}_{3}$ Powders: Determination of Sintering Parameters Yielding Nanostructured Ceramics. J Am Ceram Soc 2006;89 (9):2689-2694.

8. Shen Z, Nygren M. Microstructural Prototyping of Ceramics by kinetic Engineering: Applications of Spark Plasma Sintering. The Chemical Record 2005;5:173-184.

9. Reed JS. Principles of Ceramics Processing. Chapter 13: particle packing characteristics. In: Wiley Inter-Science $2^{\text {nd }}$ Edition; 2005:213-230.

10. Zdaniewski WA, Kirchner HP. Joining of Alumina Ceramic by Inducing Localized Reducing Conditions. J Am Ceram Soc 1987;70(1):C-4 - C-6. 
11. Moya JS, Rodriguez-Suarez T, Lopez-Esteban S, Pecharromán C, Diaz LA, Torrecillas R, Nygren M. Diamond-like hardening of alumina/Ni nanocomposites. Adv Eng Mat 2007;9(10):898-901.

12. Ebrahimi ME, Chevalier J, Fantozzi G. R-curve evaluation and bridging stress determination in alumina by compliance analysis. J Eur Ceram Soc 2003;23(6):943949.

\section{FIGURE CAPTIONS}

Fig. 1. Optical micrographs corresponding to the cross-sections of (a) $\mathrm{Al}_{2} \mathrm{O}_{3} / 2.5$ vol. $\%$ $\mathrm{nW}$ processed according to route (1), (b) 4 vol. \% $\mathrm{nW}$ composite processed according to route (2) and (c) 4 vol. \% $\mathrm{nW}$ processed according to route (3), SPSed at $1350^{\circ} \mathrm{C} / 3 \mathrm{~min} / 100 \mathrm{MPa}$.

Fig. 2. SEM micrographs corresponding to fracture surfaces of $\mathrm{Al}_{2} \mathrm{O}_{3} / \mathrm{W}$ composites with a metallic content of 2 vol. \% (processed according to route (2) and SPSed at $\left.1350^{\circ} \mathrm{C} / 3 \mathrm{~min} / 100 \mathrm{MPa}\right)$. (b), (c) and (d) are close-ups from (a).

Fig. 3. TEM images corresponding to alumina/2 vol. $\% \mathrm{~W}$ composite processed by route (2) and SPSed at $1350^{\circ} \mathrm{C} / 3 \mathrm{~min} / 100 \mathrm{MPa}$, where (a) corresponds to the inner part of the large alumina aggregates and (b) to the outer part. It could be determined that $\mathrm{W}$ concentration was $50 \%$ theoretical ( 1 vol. \%) and W nano-particles size was around 16 $\mathrm{nm}$. 
Fig. 4. SEM micrographs of the fracture surfaces corresponding to (a) the dense surface of alumina/ 2.5 vol. $\% \mathrm{~W}$ composite, (b) the porous core for the same probe obtained according to route (1) and (c) alumina/4 vol. \% W processed by (3), SPSed $1350^{\circ} \mathrm{C} / 3 \mathrm{~min} / 100 \mathrm{MPa}$. For comparison, (d) corresponds to monolithic alumina SPSed at $1350^{\circ} \mathrm{C} / 3 \mathrm{~min} / 100 \mathrm{MPa}$.

Fig. 5. SEM fracture surfaces corresponding to (a) monolithic alumina and (b) alumina/4 vol. $\% \mathrm{~W}$ composite SPSed at $1400^{\circ} \mathrm{C} / 3 \mathrm{~min} / 60 \mathrm{MPa}$.

Fig. 6. X-Ray patterns corresponding to the cross-sections of (a) the dense surface of alumina/ 2.5 vol. $\% \mathrm{~W}$ processed according to route (1), (b) alumina $/ 2 \mathrm{vol.} \% \mathrm{~W}$ dense composite processed according to route (2) and (c) alumina/4 vol. \% $\mathrm{W}$ processed according to route (3), where $\mathrm{W}_{2} \mathrm{C}$ formation during SPS at $1350^{\circ} \mathrm{C} / 3 \mathrm{~min} / 100 \mathrm{MPa}$ is shown.

Fig. 7. (a) Hardness and (b) toughness values as a function of metal content for different alumina/W composites.

\section{TABLE CAPTION}

Table 1. EDS-analysis for two representative areas (inter- and intra-aggregate) of an alumina/2 vol. \% W SPSed compact. Elements concentrations are displayed in net counts. 
Figure 1
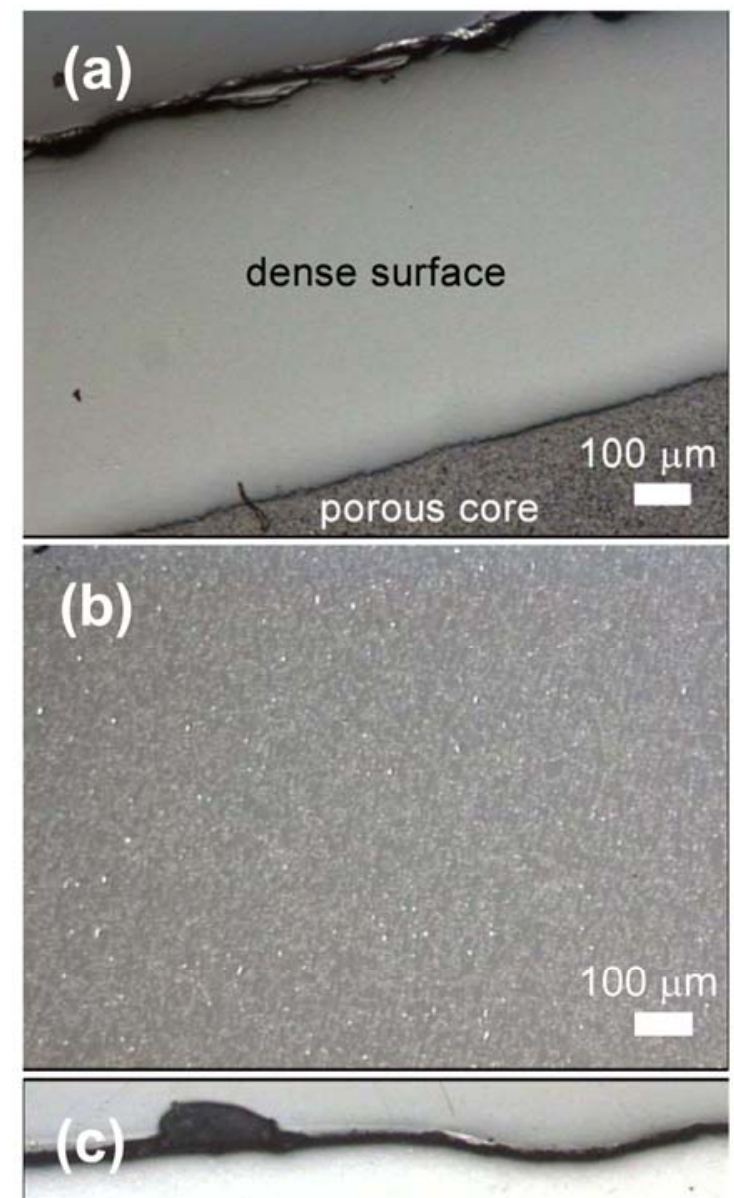

dense surface

Figure 2
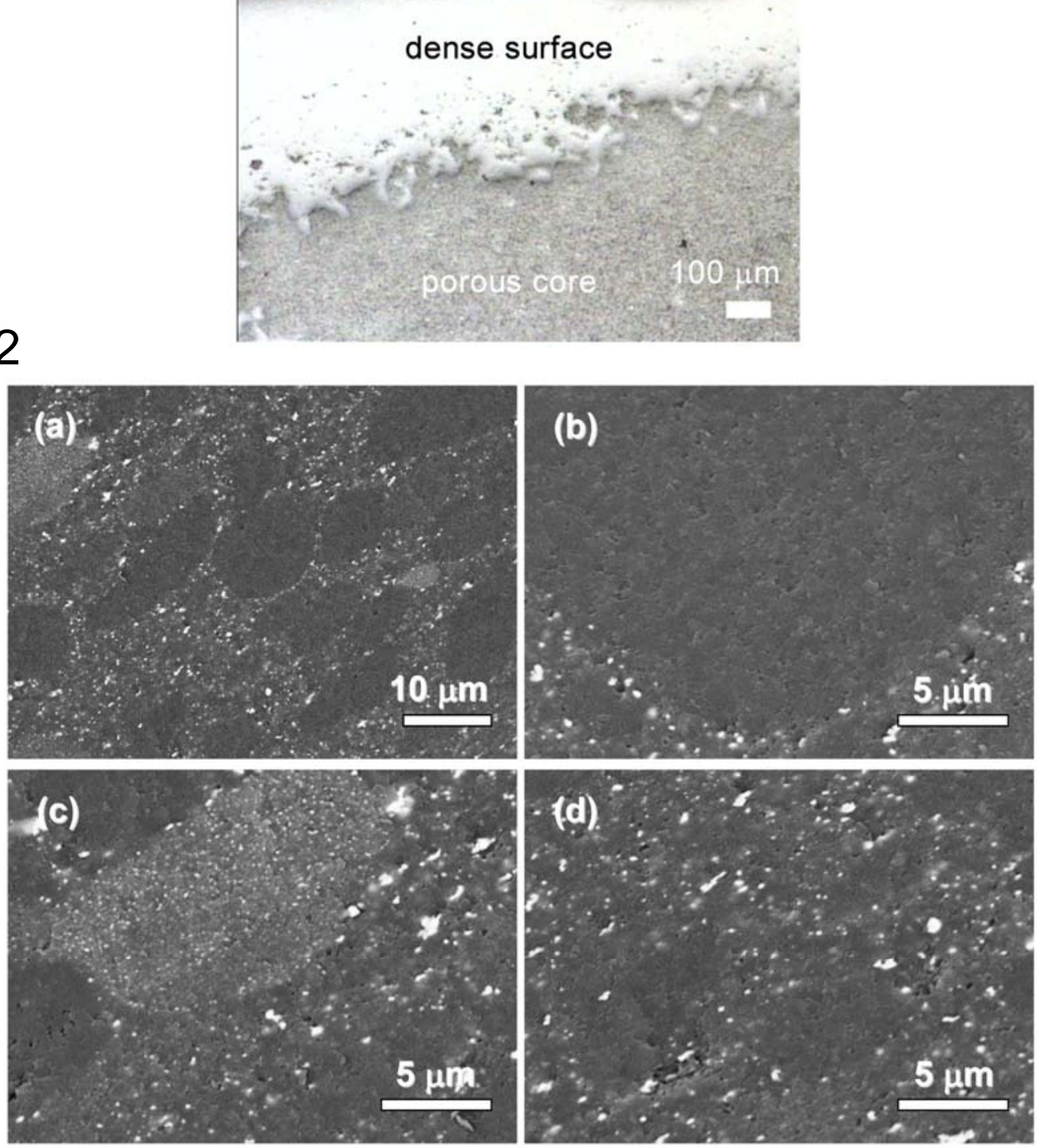
Figure 3
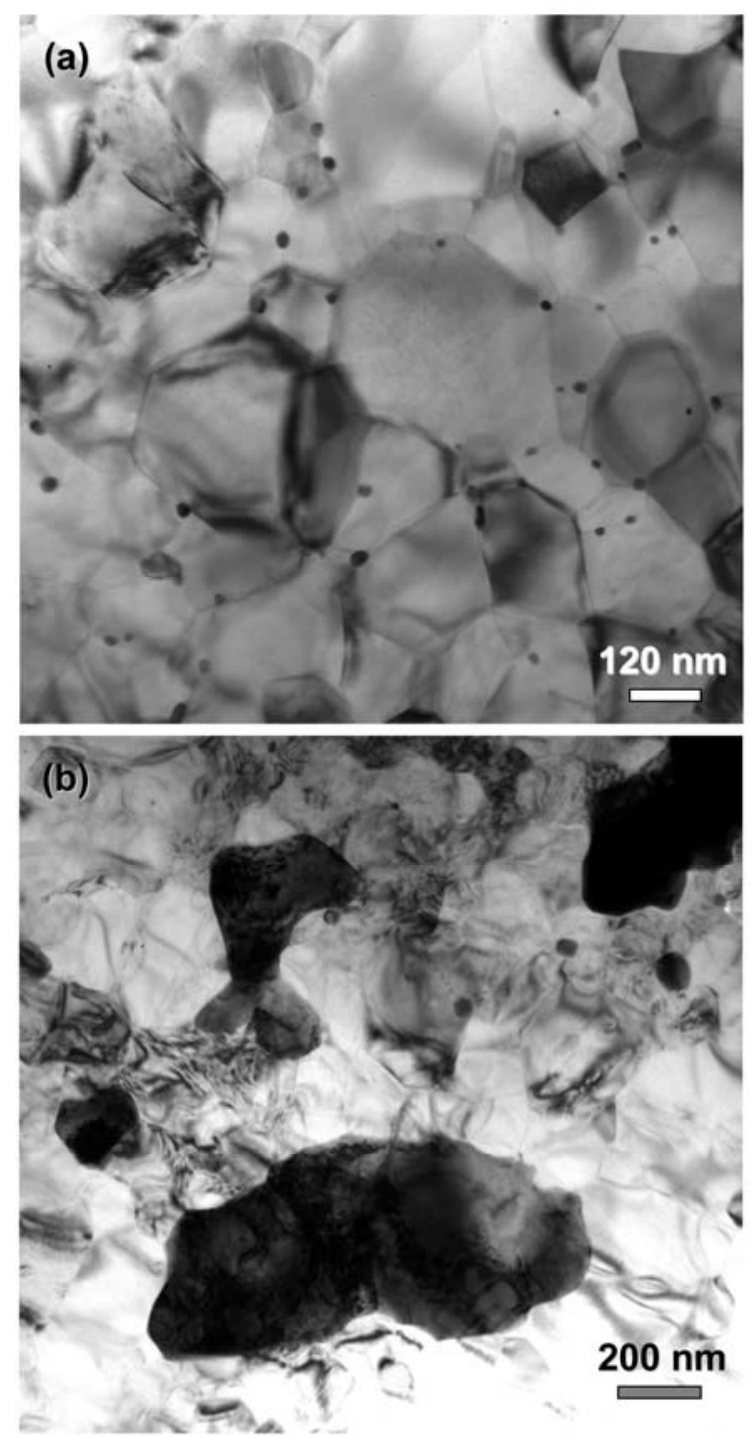

Figure 4
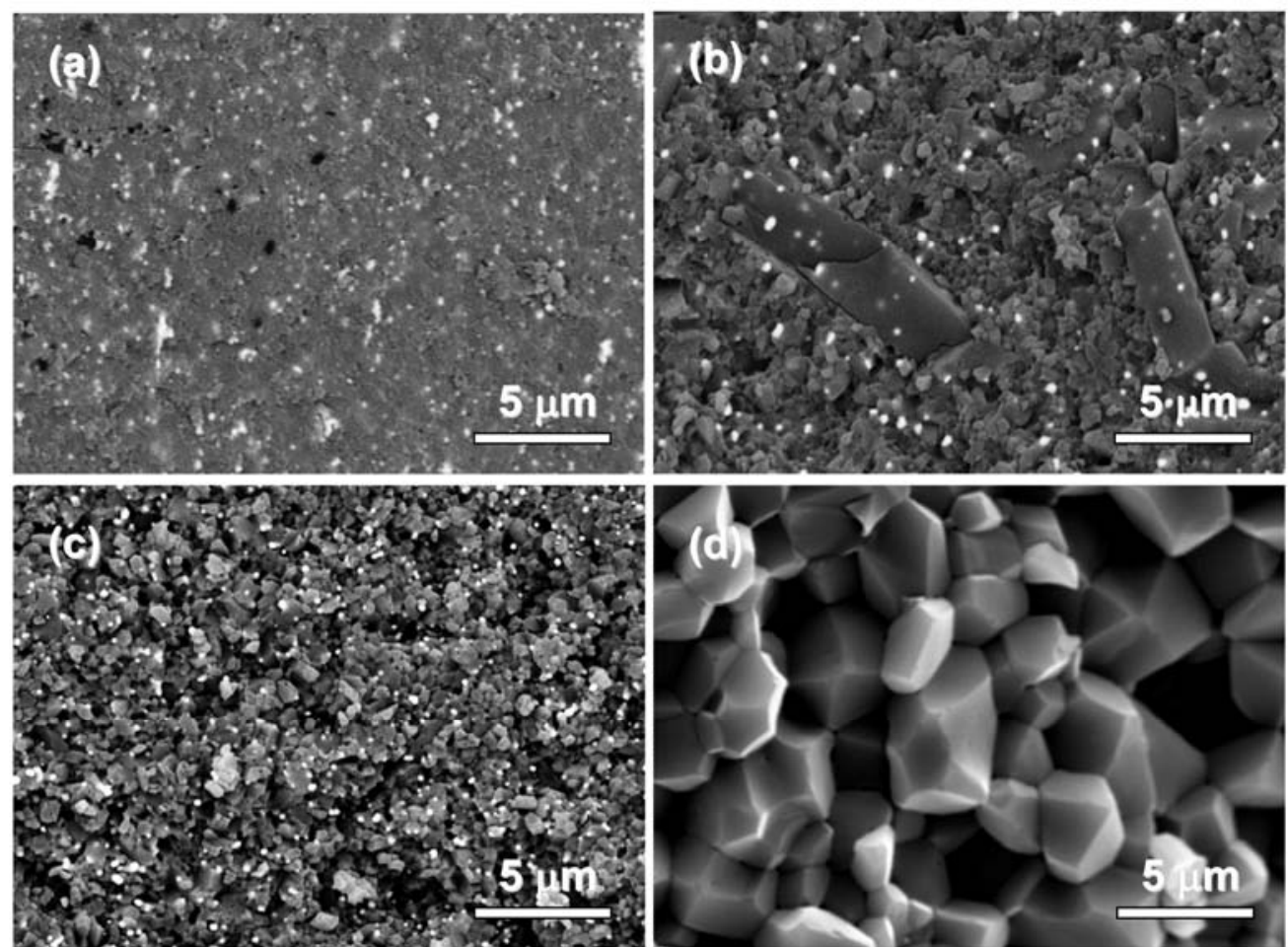
Figure 5

Figure 6
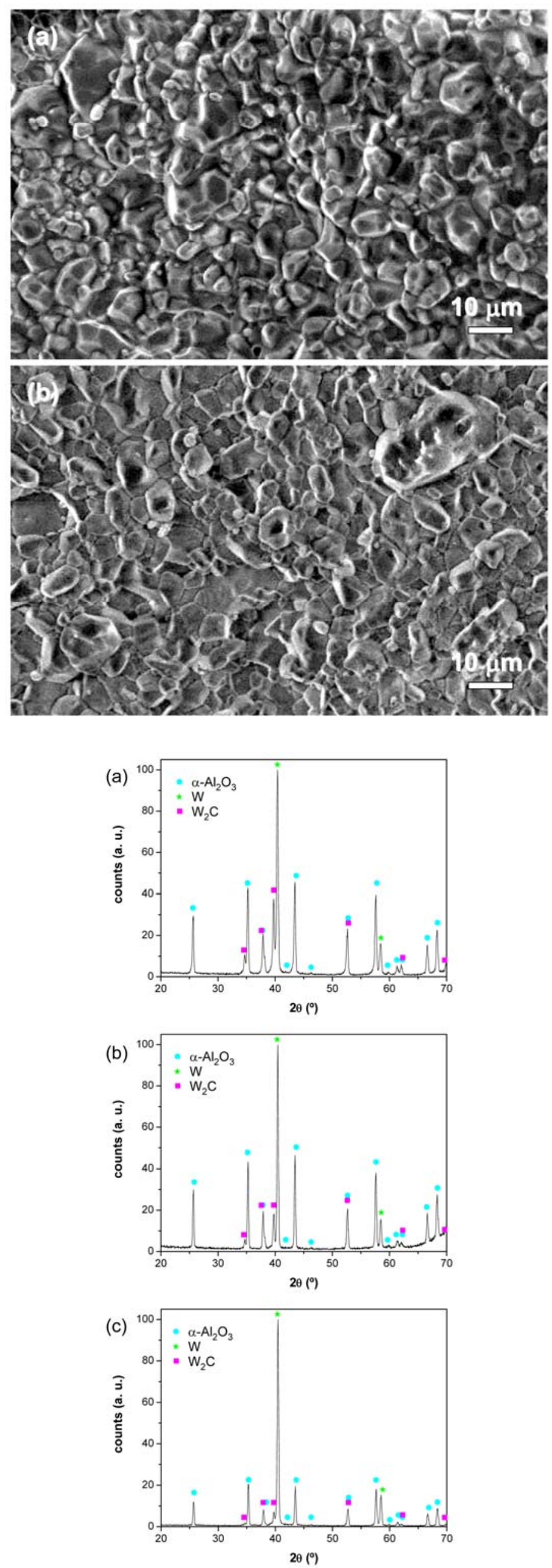


\section{Figure 7}
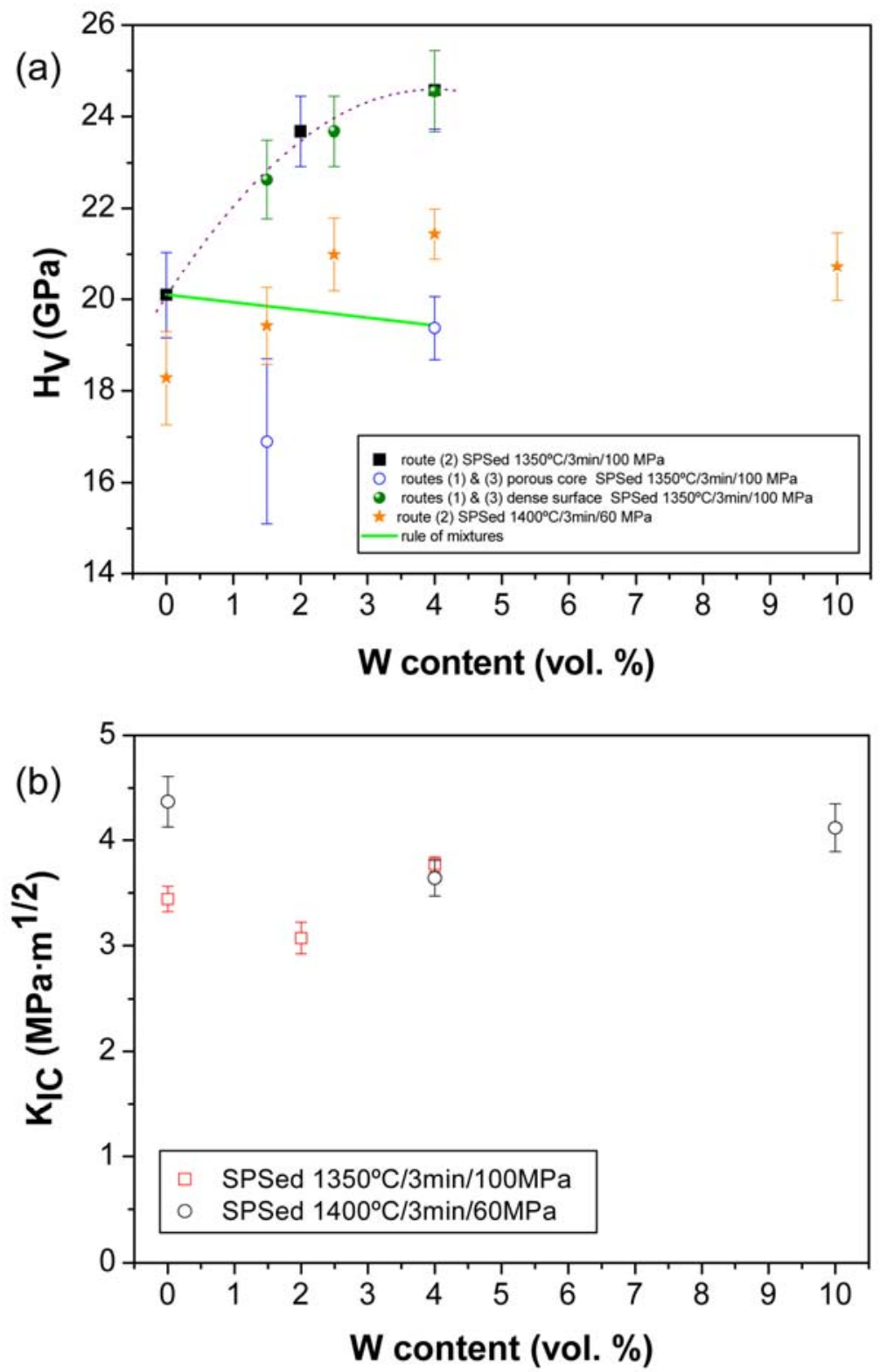

Table 1

\begin{tabular}{|l|c|c|c|}
\hline & O-K & Al-K & W-L \\
\hline Intra-aggregates area & 453 & 21631 & 530 \\
\hline Inter-aggregates area & 327 & 17489 & 1808 \\
\hline
\end{tabular}

